\title{
Mundo como fundamento da psicoterapia de grupo fenomenológica
}

\section{World as the basis of phenomenological psychotherapy group}

\author{
Luís Eduardo Franção Jardim* \\ LABI-USP/Universidade Paulista - UNIP, São Paulo, São Paulo, Brasil
}

\begin{abstract}
RESUMO
Neste trabalho pretendemos relacionar o mundo da fenomenologia de Martin Heidegger às características de psicoterapia de grupo, enquanto fundamento essencial para essa modalidade terapêutica. Mundo abarca a totalidade do ser-com os outros, ser junto aos entes e ser si mesmo. Não há como pensar o Dasein destituído de mundo, tampouco mundo sem Dasein. Inserido em uma rede de significações compartilhadas, somos nosso próprio mundo, no qual nos relacionamos e conhecemos. Somos constituídos a partir das relações com os outros e somente nas relações que acessamos nosso modo de ser. Em grupo, abre-se a possibilidade de entrarmos em contato com nossas próprias referências de mundo, que constituem nosso existir e nossa compreensão de si mesmo. Nesta modalidade de atendimento, estabelecese um mundo compartilhado terapêutico a partir de uma disponibilidade específica à escuta de si mesmo e do outro.
\end{abstract}

Palavras-chave: psicoterapia de grupo, fenomenologia, mundo, Martin Heidegger.

\begin{abstract}
In this paper we intend to relate the Martin Heidegger's phenomenology world to the characteristics of group therapy, as basis for this therapeutic modality. World encompasses the totality of being with others, beingalongside and being yourself. There is no Dasein without world, nor world without Dasein. Inserted into a network of shared meanings, we are our own world in which we relate and know. We are constituted from relationships with others and only in the relations we access our ways of being. In a group, it is possible to get in touch with our own reference of world, which determines our existence and our understanding of ourselves. In this modality of therapy of care, a therapeutic shared world is established from an availability to listen to yourself and others.
\end{abstract}

Keywords: group psychotherapy, phenomenology, world, Martin Heidegger. 


\section{É só quando esquecemos todos os nossos conhecimentos é que começamos a saber Clarice Lispector}

O objetivo deste artigo é apresentar e desenvolver alguns aspectos de mundo tal como concebido por Martin Heidegger, como fundamentação de uma psicoterapia de grupo, a partir da fenomenologia hermenêutica. Entendemos que no contexto de grupo, a fenomenologia se mostra como um recurso para lidarmos com o achatamento da singularidade do homem e com a uniformização do olhar para o humano, característico da era da técnica, na qual estamos inseridos. No âmbito psicoterapêutico, o olhar para o fenômeno de grupo, a partir do fundamento heideggeriano de mundo, possibilita estabelecer no grupo um microcosmo de manifestação e compreensão terapêutica do modo de ser dos membros a partir dos acontecimentos no aqui-e-agora.

Quando falamos em fundamentação fenomenológica da psicoterapia de grupo, estamos falando do pano de fundo no qual se assenta essa prática clínica e a compreensão dos acontecimentos que ali se dão. $\mathrm{Na}$ medida em que Heidegger não pretendia, e tampouco desenvolveu uma teoria sobre o homem, não estamos aqui lidando com uma teorização de uma prática psicoterapêutica a partir de seu pensamento.

Por essas características, em alguns momentos, poder-se-ia traçar um paralelo do trabalho de fundamentação de uma terapia de grupo fenomenológica com outros âmbitos de criação, como nas artes. Quando um artista se debruça sobre um trabalho, primeiramente esboça linhas iniciais para que a partir delas se crie a obra. Não se tratam de linhas que delimitam, que restrinjam um fazer, mas linhas que fundam uma região como horizonte, para que a partir delas emerja a obra a partir do caráter poético da arte, rompendo seus traços e recriando aquela região. A obra de arte não é determinada previamente pelos rascunhos iniciais, mas eles também já partem de uma irrupção do que virá a ser a obra e transitam sobre ou reconfiguram os rabiscos iniciais.

No contexto da psicoterapia de grupo, sua fundamentação fenomenológica acontece com alguns pontos convergentes. Os delineamentos traçados aqui não dizem de uma determinação do que pode acontecer no encontro do grupo, tampouco estas linhas restringem a compreensão a um saber teórico sobre o homem. Mas o que aqui é delineado diz do lugar de escuta do coordenador, ou psicoterapeuta de grupo. O preenchimento e ruptura dessas linhas esboçadas inicialmente se dão apenas no acontecer mesmo do grupo, nas trocas e nas relações entre os membros. 
Devido às restrições pertinentes a um artigo, neste curto espaço não será apresentado um tratado abarcando "todos" os traços que caracterizam a psicoterapia de grupo para a fenomenologia, muito menos um compêndio sobre mundo heideggeriano. Trata-se aqui de um recorte de algumas características fundamentais de mundo e como esses aspectos estão manifestos no contexto psicoterapêutico de grupo.

A Fenomenologia-Hermenêutica heideggeriana fundamenta um modo de pensar o homem que, na psicoterapia de grupo, surge como uma possibilidade de estar aberto para a intimidade e recuperação de si mesmo. No cenário técnico atual em que vivemos, identificamos de modo crescente o fenômeno descrito por Heidegger $(2004$; 2007) como "desertificação" humana, no qual as relações de mundo constituem-se progressivamente de modo mais distanciado e impessoal. O homem contemporâneo parece cada vez mais fechado em si mesmo e, as comunicações, trocas de experiências e afetos tornam-se mais raros ou formatados pelo aparato tecnológico.

Para Heidegger, "o mundo do Dasein é mundo compartilhado" (1998, p.170, tradução modificada ${ }^{1}$ ) e, no mundo em que o Dasein (ser-aí) habita, a todo o momento está em relação com o outro e com si mesmo. Os modelos de relação referidos acima são modos contemporâneos possíveis de relação com o outro. E, longe de submetê-los a um julgamento de valor, cabe apenas analisar suas possibilidades, perdas e ganhos. Embora esta "nova" roupagem do contato humano virtual traga muitas possibilidades diferentes de relação - as quais não podemos negar sua importância no mundo contemporâneo -, essas comunicações podem também favorecer um empobrecimento da proximidade nas relações e a quase extinção do caráter de intimidade no contato.

A terapia de grupo fenomenológica não tem uma proposta de recuperação de um suposto "ideal" de relação, tampouco a busca por algo que pudesse ter sido perdido ao longo da história da era da técnica.

O grupo se configura inicialmente como uma abertura compartilhada e privilegiada na qual podem se desvelar modos de ser possíveis no momento mesmo em que acontecem na relação com o outro. E nesta revelação de modos de ser, abre-se a possibilidade de serem apropriados e, com isso, lidar com eles mais livremente.

Para entendermos o que vem a ser o grupo como abertura compartilhada privilegiada, precisamos antes esclarecer o que significa dizer que o mundo do Dasein é um mundo compartilhado.

Primeiramente, a ligação entre Dasein e mundo não deve ser entendida a partir dos moldes da relação sujeito-objeto. Tampouco podemos conceber o Dasein como um ente que venha a ter um mundo, ao qual pode ligar-se ou não de acordo com sua própria vontade. Por esta última perspectiva, entenderíamos o mundo como 
uma "propriedade" do Dasein, a qual poderia lançar mão em determinado momento. Ao contrário, o Dasein está intrinsecamente ligado ao mundo e vice-versa. Não há como pensar Dasein destituído de mundo, do mesmo modo que não faz sentido pensar o conceito de mundo sem o Dasein.

O Dasein está no mundo. O caráter fundamental de ser-em um mundo se refere ao sentido de habitar e diz: "eu moro, me detenho junto... ao mundo, como alguma coisa que, deste ou daquele modo, me é familiar" (Heidegger, 1998, p.92). Estar no mundo significa habitar o mundo no qual desde o início já existo. A existência do Dasein somente se dá, sempre e a cada vez, em um mundo, de modo que, o ser-no-mundo é a constituição fundamental do Dasein. Quando dizemos Dasein, já visamos de imediato que "a ligação com o mundo é um traço essencial do ser-aí mesmo e, porque não dizer, é sua constituição essencial marcante. Ser-aí não significa nada senão ser-no-mundo" (Heidegger, 2008, p.324). Na medida em que ser-nomundo é um traço fundamental do Dasein, não faz sentido perguntar se há uma relação do Dasein com o mundo. Dasein já significa serno-mundo.

Enquanto ser-no-mundo, o Dasein projeta-se em possibilidades e isso não é algo que se dê como que pairando no ar, mas a existência se dá, sempre e a cada vez, no mundo. Em outras palavras, a existência somente acontece facticamente. Existo sempre já lançado em um mundo de significatividade compartilhada no qual habito. O caráter de ser-lançado (Geworfenheit) pertence ao Dasein enquanto ser-nomundo. Desde o início, o Dasein já foi lançado em um mundo sem que tenha anteriormente decidido sobre seu próprio lançamento e, por isso mesmo, nunca pode estar aquém do seu lançamento.

Para Heidegger,

mundo é o todo da constituição ontológica. Ele não é apenas o todo da natureza, da conivência histórica, do próprio ser-simesmo e das coisas de uso. Ao contrário, ele é a totalidade específica da multiplicidade ontológica que é compreendida de maneira una no ser-com os outros, no ser junto a e no ser-si- mesmo (Heidegger, 2008, p. 328).

O mundo é o lugar ontológico aberto, o aí (Da), no qual o Dasein (ser-aí) tem acesso e pode compreender os entes e a si mesmo. Lançado em um mundo compartilhado, o Dasein se relaciona e se comporta junto aos entes intramundanos, com os outros Dasein e consigo mesmo. Pertence ao ser-no-mundo o caráter de ser junto aos entes, ser-com os outros e ser-si-mesmo.

Na perspectiva do atendimento em grupo fenomenológico, na base do "microcosmo" que é criado, está o fundamento do ser-no-mundo em que "o mundo é sempre o mundo compartilhado com os outros. O ser-em é ser-com os outros" e "os outros [...] são aqueles dos quais, 
na maior parte das vezes, ninguém se diferencia propriamente, entre os quais também se está" (Heidegger, 1998, p.169-70).

Em sua constituição fundamental, Dasein é sempre ser-com os outros e isso quer dizer que está, a cada vez, em um modo possível de relação com o outro. Ser-com significa que o Dasein é determinado existencialmente por esse aspecto, mesmo quando o outro não é dado ou percebido facticamente.

"Dentro do mundo, esse Dasein compartilhado dos outros só se abre para o Dasein e assim também para os co-existentes". (Heidegger, 1998, p.172, tradução modificada). Para Heidegger, é no estar com o outro que temos uma referência de nós mesmos, o outro dá a medida do meu si mesmo. Na relação com o outro, o Dasein pode perder-se no acolhimento familiar do a gente impessoal, mas também abre a possibilidade de encontrar-se.

A possibilidade de encontrar-se, de ser resoluto, não significa que Dasein seja retirado do mundo ou da cotidianidade. Muito pelo contrário, para Heidegger, "a existência própria não é algo que paire por sobre a de-cadência do cotidiano. Em sua estrutura existencial, ela é apenas uma apreensão modificada da cotidianidade" (1998, p.241). Portanto, a resolução não retira o Dasein da convivência com o outro, nem da lida com os utensílios lançando-o em algum suposto "mundo paralelo". Como uma modificação do cotidiano, a propriedade acontece nas relações, na lida e na solicitude cotidianas.

Deste modo, o poder-ser mais próprio é um modo de relação com suas próprias possibilidades, e isso acontece no mundo. O Dasein somente pode se apropriar de si mesmo no seu cotidiano, isto é, como ser-no-mundo, o que significa: na relação com o outro, junto às coisas e com si mesmo. Somente podemos existir de um modo singular ou apropriado de si mesmo, se for com o outro, pois essa é a característica fundamental do Dasein. É a partir do outro que conhecemos o si mesmo.

Para Heidegger, mundo é "aquilo a partir do qual o ser-aí se dá a entender a que ente pode dirigir-se seu comportamento e como se pode comportar com relação a ele" (Heidegger, 1973, p.313).

Habitando um mundo compartilhado, o Dasein é sua própria abertura e com os outros estabelece uma abertura comum, na qual os entes e o outro vêm ao encontro. O mundo do Dasein é determinado, primeiramente, pela sua abertura. Isso significa que o Dasein não possui uma tal abertura que esteja em contato com um mundo, o Dasein não tem uma abertura, muito pelo contrario, "o Dasein é sua abertura" (Heidegger, 1998, p.186, tradução modificada). Ser sua própria abertura aponta para o "aí" $(D a)$, o lugar aberto ao qual existe facticamente e pelo qual está a cada vez junto aos entes e aos outros. Dasein já sempre é nesse aí na medida em que a abertura, o " $a i^{\prime \prime}$, é condição de possibilidade de compreensão do mundo e, portanto, de si mesmo e dos outros. 
Na facticidade, o Dasein já se encontra em um mundo a partir de sua abertura. O Dasein descobre a si mesmo em suas possibilidades já sidas sempre e a cada vez a partir da abertura do seu aí. Na coexistência do Dasein, é constituída também uma abertura comum composta por aqueles que estão se relacionando. Em outras palavras, na relação com o outro, compartilhamos um lugar comum em que as coisas a cada vez aparecem para nós.

No contexto da terapia em grupo, trata-se, de uma abertura compartilhada entre todos os membros. Apesar de não se caracterizar como um espaço terapêutico com um suposto "objetivo" de apropriação, muito antes, o grupo terapêutico se constitui como uma co-abertura, um espaço de "mostração" em grupo, no qual os outros "vêm ao encontro a partir do mundo em que o Dasein se mantém de modo essencial" (Heidegger, 1998, p.170, tradução modificada) e que, a partir da relação com o outro, pode revelar-se o si mesmo de cada um em seus modos de ser. O grupo caracteriza-se, assim, como uma abertura compartilhada, um aí ( $D a)$ compartilhado. No caso da terapia em grupo, quais aspectos deste compartilhamento a diferenciam de um outro grupo qualquer? Em um grupo terapêutico o contato com o outro se estabelece com outras características. Para explicitar essas características, será focado nesse momento no que aqui é referido como "aí terapêutico".

o "aí terapêutico" diz respeito a abertura mesma constituída na relação estabelecida em terapia; é o espaço de revelação do modo de ser do membro do grupo e de explicitação do sentido que permeia cada experiência relatada. É o psicoterapeuta quem sustenta aberto esse aí terapêutico enquanto uma "área" de confiança na qual cada membro pode circular e encontrar sua medida de contato e aproximação com si mesmo.

Enquanto uma abertura compartilhada, constituída a partir da abertura de cada um dos membros do grupo, o aí terapêutico também é constituído ontologicamente pela disposição (Befindlichkeit), compreensão (Verstehen) e discurso (Rede). Não há como separar cada um destes constituintes da abertura do Dasein, uma vez que os três são aspectos co-originários e acontecem ao mesmo tempo.

A disposição é um existencial constituinte da abertura do Dasein e, portanto, um caráter ontológico deste ente. Como todo constituinte ontológico da abertura do aí ( $D a)$ do Dasein, a disposição também possui um correspondente ôntico. Interessa ao presente trabalho estudar seu correspondente ôntico, a afinação (Stimmung). A afinação, enquanto a referência ôntica da disposição, é o que há de mais cotidiano e conhecido para o existir. A todo e qualquer momento o Dasein é transpassado por uma afinação, um modo de estar afinado. A cada vez, o Dasein está em uma determinada afinação, porém, ela não deve ser confundida com qualquer psicologia das 
emoções ou afecções. A afinação é mais originária que um humor ou uma emoção psicológica e isso quer dizer que somente existem estados psicológicos, porque, primeiramente e a cada vez, o Dasein é afinado de um modo ou de outro.

O Dasein está sempre afinado de determinado modo. A cada vez, o Dasein já se encontra em uma ou outra afinação, mesmo quando cotidianamente transita de um marasmo corriqueiro para uma falta de ânimo, quando de mau humor ou quando não apercebe-se de tais fenômenos. Do ponto de vista ontológico, esse transitar entre diferentes modos de estar afinado apenas comprova que o Dasein está sempre em uma determinada afinação (Heidegger, 1998, p.188, tradução modificada).

No encontrar-se em uma disposição, afinado mais densa ou euforicamente, o peso da responsabilidade de ser seu próprio aí pode ser intensificado ou aliviado. Como alívio ou como fardo, essas possibilidades de afinação revelam o caráter de peso do Dasein. A possibilidade de saber-se em uma afinação é nublada se comparada à "abertura originária das afinações, em que o Dasein se depara com seu ser enquanto aí [...] A afinação evidencia "como alguém está e se torna". É nesse "como alguém está" que o estar afinado traz o ser para o seu 'aí'" (Heidegger, 1998, p.188, tradução modificada). O Dasein, enquanto ente entregue à responsabilidade de, existindo, ter de ser, já se abriu em uma sintonia com uma afinação na afinabilidade (Gestimmtheit), isto é, no caráter de estar afinado.

Para Heidegger, "a abertura do co-Dasein dos outros, pertencente ao ser-com, significa: na compreensão do ser do Dasein já subsiste uma compreensão dos outros porque seu ser é ser-com. [...] Este conhecer-se está fundado no ser-com que compreende originariamente" (1998, p.176, tradução modificada). Mas a compreensão nunca é separada da afinação. Muito pelo contrário, a compreensão é sempre afinada. A afinação é o determinante ôntico da compreensão, e isto quer dizer que a todo momento, as afinações é que abrem a compreensão para a percepção de uma coisa ou outra. Tudo que compreendemos no mundo, isto é, das coisas, dos outros e de nós mesmos está tingido pelo modo como já estou afinado. E como não poderia ser diferente, na psicoterapia, as afinações também afinam o setting a todo o momento e são os determinantes do que se mostra e do que é compreendido de si mesmo.

Mas como se estabelece esse aí terapêutico? Além das afinações características de cada um dos membros e do psicoterapeuta, em uma abertura terapêutica já existe de antemão uma afinação com a particularidade de uma certa disponibilidade por parte dos membros e terapeuta para aquele tipo de encontro. Na constituição de um grupo terapêutico, já há um tipo de expectativa para esta modalidade de encontro que permeia a possibilidade terapêutica e que se constitui em uma afinação anterior. 
Na psicoterapia individual, é fundamental para o analisando que se estabeleça uma relação de confiança. A confiança abre a possibilidade de auto-revelação. É na confiança que pode surgir o relato de algo de si, ou um acontecimento, mas no momento em que é contado, não é vivido aquilo mesmo relatado. Esta fala parte de um lugar seguro, o lugar da confiança, sobre algo que já se deu determinado por uma afinação de outro momento. Parte do trabalho do psicoterapeuta também é caracterizado por contribuir para que o analisando possa recuperar, naquilo que está relatando, o impacto experimentado na situação e acesse a região de origem da afinação presente naquele relato. Abrindo-se, assim, a possibilidade de responsabilizar-se por si mesmo e, talvez inaugurar uma nova articulação em seu modo de estar no mundo.

No contexto de psicoterapia de grupo, esse processo de construção de confiança é obviamente mais difícil pela própria complexidade das relações. Neste processo, não se trata da relação entre duas pessoas, mas da co-existência de todo um grupo. A complexidade do grupo não está somente no estabelecimento da confiança, mas é necessário também que o grupo se configure como um espaço de afeto, de compreensão recíproca da experiência um dos outros e, principalmente, de lidar com as diferenças.

A relação de confiança não acontece apenas da parte de um membro do grupo com o psicoterapeuta, mas além do psicoterapeuta, também com cada outro membro e com o grupo como um todo. Nesta relação, para cada um, escutar o outro tem tanta importância quanto expressar-se. 0 grupo não tem um sentido único, mas as relações se estruturam a partir de uma multiplicidade de afinações e modos de ser presentes naquele mundo compartilhado do grupo.

Em grupo, a confiança tem um desdobramento peculiar. $\mathrm{Na}$ psicoterapia de grupo, a confiança não é apenas um espaço para falar sobre um ocorrido, um relato de uma experiência anterior. Mas conseguindo-se estabelecer um espaço de acolhimento e confiança entre os membros daquele microcosmo, abre-se também para que cada um seja tal como ele é na relação de um com o outro. O que isso significa?

No §26 de Ser e tempo, Heidegger descreve a solicitude (ou preocupação) em seus modos positivos que, em diferentes graus, se dão de formas mistas entre dois modos extremos: solicitude substitutiva (ou dominadora) e solicitude liberadora (Vorspringende Fürsorge). O primeiro modo caracteriza-se por fazer pelo outro, no lugar do outro, o que pode retirar do outro a responsabilidade perante seu próprio poder-ser, enquanto o segundo parte de uma convivência mais própria, em que cada um pode ser-com o outro a partir de si mesmo.

Fundamentado nestes modos positivos da convivência descritos por Heidegger, Jardim (2003) os relaciona ao contexto da psicoterapia. 
Para o autor, o psicoterapeuta evita substituir o outro em sua tarefa de ser, buscando liberá-lo para a compreensão de si e para responsabilizar-se pelo seu modo de ser. $O$ modo de se dar específico da relação psicoterapêutica é derivado, ontologicamente, da solicitude com o outro denominada solicitude liberadora, ou antecipadora.

Na relação e na escuta terapêutica em grupo, o psicoterapeuta não toma para si a responsabilidade perante o si mesmo dos membros, não faz pelo outro, mas, ao contrário, sustenta uma postura de, no encontro, deixar-ser o outro tal como ele é e devolver, assim, ao outro a responsabilidade perante ele mesmo.

Em todas as relações, transita-se sempre em modos mistos desses dois extremos positivos de relação. O psicoterapeuta não deixa de "fazer pelo outro" quando sustenta uma determinada característica de abertura de compreensão em grupo, mas, em ultima instância, a postura terapêutica pretende que cada um possa, em seu ritmo, ser entregue à responsabilidade de ser si mesmo e assumir a própria existência enquanto tarefa. Como se a postura do terapeuta se colocasse em uma espécie de "tendência" a uma solicitude liberadora. A relação entre um e outro fundada na solicitude liberadora não é um modo exclusivo da prática clínica, e tampouco uma relação certa e definida. No contexto estudado, devemos entender esse modo de se relacionar como fundamento de uma postura que é tomada pelo psicoterapeuta. Quanto mais o psicoterapeuta conseguir estabelecer uma convivência própria e liberadora com o outro, maior a possibilidade de que esse encontro venha a ter o caráter de deixar o outro ser em seu mais próprio poder-ser (Jardim, 2003). O encontro em grupo é um deixar-ser ele mesmo em que o outro pode se libertar para sua própria existência.

No aí terapêutico de grupo, o coordenador deve buscar sustentar ao máximo essa postura dentre os modos mistos de relação. Desde o primeiro momento esse modo de deixar o outro ser a partir dele mesmo já deve permear a característica das relações do grupo. Concomitantemente, o estabelecimento da confiança em grupo favorece que as questões significativas de cada um venham não apenas pela reflexão de um falar sobre, mas principalmente no momento mesmo em que o grupo acontece. No acontecer ao vivo grupal, as relações permitem que emerjam o modo de ser de cada um durante a troca, a fala e mesmo a escuta do que o outro diz.

Nesse encontro, a compreensão buscada não está voltada só para o conteúdo do relato das reflexões e "eventos" trazidos à sessão pelos membros do grupo, mas trata-se de uma escuta atenta para o sentido que sustenta tal relato ou acontecimento possui para aquele 0 experienciou. A escuta terapêutica está atenta para o fenômeno que se mostra, através das relações do grupo. 
O sentido que se dá nos acontecimentos em grupo, muitas vezes ainda encoberto, revela ao psicoterapeuta e ao grupo o modo como o grupo e cada membro se relaciona com seu mundo, isto é, o modo de ser que se apresenta no aqui-e-agora das relações. O desvelamento desse modo de ser pode abrir para os membros a possibilidade de se apropriar de si mesmo e se responsabilizar pelo seu próprio ser.

A psicoterapia de grupo é descrita até aqui como um lugar de aparecimento dos modos de ser de cada membro e do grupo como um todo, favorecido por uma postura liberadora. Nesse lugar de aparecimento de modos de ser, busca-se a compreensão do sentido que se revela na experiência e nas relações entre os membros. A partir da revelação e compreensão do sentido, abre-se a possibilidade de apropriação de si mesmo e responsabilização pelo próprio existir.

O fundamento ontológico deste entendimento do modo de acontecer da psicoterapia de grupo é o mundo e as relações de mundo, tal como pensados por Martin Heidegger. Essa compreensão da psicoterapia de grupo parte das relações que acontecem em grupo, a partir das quais revela-se o sentido mesmo da experiência. Nesta medida, mundo, enquanto fundamento, possibilita pensar a psicoterapia de grupo e os fenômenos que ali se mostram de um modo fenomenológico, não atrelado ao caráter reificante das teorias psicológicas tradicionais e livre de uma tendência humanista, centrada na pessoa.

A fundamentação no mundo heideggeriano, possibilita a ruptura do entendimento da psicoterapia de grupo como o somatório de terapias individuais. É na convivência que se estabelece no microcosmo da psicoterapia de grupo que 0 sentido pode se mostrar. 0 desvelamento de modos de ser em grupo acontece a partir das relações e nas relações.

Os modos de ser que se explicitam, não só ao psicoterapeuta, mas também ao grupo, são transpassados por um jeito de estar afinado. Este jeito abre suas possibilidades de compreensão de si mesmo e de relacionar-se com o mundo e com os outros. Estas afinações constituintes da existência de cada um podem ser percebidas no momento em que se mostram pela fala, pelo comportamento, pelo olhar, pelo corpo, pelo gesto etc.

No contato ao vivo, abre-se a possibilidade de explicitação para o próprio membro do seu modo de ser, isto é, na relação com o grupo pode compreender a si e responsabilizar-se por como percebe 0 mundo a cada vez.

$\mathrm{Na}$ escuta do que se revela em grupo, "a coisa fala a mim. Se compreendermos a linguagem do dizer no sentido de se deixar mostrar como algo, então perceber é sempre linguagem e ao mesmo tempo dizer palavras" (Heidegger, 2006, p.215).

Se levarmos em conta que a ação e relato do membro do grupo está perpassado e tonalizado, do início ao fim por afinações, temos acesso 
mais claramente ao seu sentido se compreendermos como está afinado.

\begin{abstract}
Uma tonalidade afetiva [afinação] é um jeito, não apenas uma forma ou padrão modal, mas um jeito no sentido de uma melodia, que não paira sobre a assim chamada subsistência própria do homem, mas que fornece para este 0 tom, ou seja, que afina e determina o modo e o como de seu ser (Heidegger, 2003a, p.81).
\end{abstract}

Entretanto, o caráter terapêutico não está somente em saber de si, em como me relaciono no mundo. Mas também é fundamental a busca por acessar o que Heidegger (2003b; 2003c) denominou como região (Gegend) de mundo em que essa abertura se originou. É nessa região que se sustenta a articulação do estar-afinado de cada um, em outras palavras, a afinabilidade (Gestimmtheit) de cada um. Compreender o sentido que sustenta este modo de estar afinado pode trazer a possibilidade de rearticular essa afinabilidade e abrir um modo mais próprio de se relacionar com o mundo.

A afinação determina a melodia na qual cada um vibra. É o tom que colore e abre a perspectiva na qual se enxerga o mundo. As possibilidades de ser do membro do grupo são sempre abertas a partir do seu mundo e, portanto, a partir do modo como está afinado. Em outras palavras, o poder-ser é determinado pelo jeito como o paciente está no mundo, configurando uma espécie de atmosfera, na qual está inserido e transpassado por seu tom (Jardim, 2009).

Em grupo não se trata apenas da afinação de cada um isoladamente. Um grupo, não só o terapêutico, estabelece uma afinação compartilhada, isto é, cada grupo como um todo tem uma atmosfera determinante das relações e dos modos de ser comum àqueles membros. Na psicoterapia de grupo a compreensão se dá a partir dessa afinação compartilhada também. O psicoterapeuta não está isento de seu caráter de estar afinado, tampouco escapa dessa afinação que se constitui em grupo. Por esse aspecto, torna-se fundamental que o psicoterapeuta tenha uma visão ampla do grupo, consiga dar "um passo para trás" e consiga perceber também como esse clima determina seu olhar.

No momento em que o próprio grupo está olhando para o grupo e discutindo como soou para cada um o que se passou ali, é esta afinação compartilhada do grupo que mais se manifesta. Manifestase, seja como determinante do olhar e compreensão de cada um sobre o grupo, mas também como o que se mostra do grupo como um todo para o grupo. Poder olhar para isso e compreender como se dá, é também um fator terapêutico na medida em que essa afinação compartilhada também determina o modo de ser de cada um em sua singularidade. 
A elaboração das afinações como constituintes da abertura de mundo e determinantes da compreensão e dos modos de ser dos membros do grupo proporciona um entendimento novo sobre o fenômeno de grupo, não pautado nas teorias psicológicas sobre comportamento de grupo. Esta elaboração aqui proposta pertence ontologicamente à fundamentação no mundo, tal como pensado por Heidegger, principalmente, na década de 1920.

Por fim, a postura fenomenológica terapêutica, como um dos aspectos mais importantes para a modalidade de atendimento psicoterápico de grupo, está refletida neste trecho de Clarice Lispector, extraído do livro "Uma aprendizagem ou o Livro dos Prazeres". Ela diz:

\section{É só quando esquecemos todos os nossos conhecimentos é que começamos a saber}

Para a relação psicoterapêutica fundamentada na fenomenologiahermenêutica de Martin Heidegger, esse lugar do não saber é o que há de mais fundamental na compreensão das possibilidades de ser do outro. Para isso, uma escuta terapêutica fenomenológica para o que se mostra no grupo não pode estar pautada em teorias psicológicas, que na busca pela generalização, achatam as particularidades e reificam a experiência mesma de cada um.

$\mathrm{Na}$ postura fenomenológica suspende-se todo conhecimento, julgamento e conceito anterior para que seja possível acessar como o mundo daqueles membros se abrem, isto é, qual é o sentido que se mostra na relação terapêutica estabelecida em grupo a partir do relato e da ação dos membros, como um todo. É somente a partir dessa postura que o psicoterapeuta e o grupo conseguem acessar 0 que emerge, o que acontece diante do grupo nos atendimentos. Pensar mundo como fundamento da psicoterapia de grupo fenomenológica significa um deixar-vir-ao-encontro dos sentidos que se desvelam nas relações e nos acontecimentos do grupo e, deste modo, rompe com a postura humanista centrada na pessoa.

Esta postura de suspensão e de não saber é fundamental para que o membro, ao se mostrar na co-abertura do grupo, possa ser compreendido e se compreenda a partir dele mesmo em seu modo de ser. Em outras palavras, para que neste espaço de escuta e revelação constituído pelo aí terapêutico, possa emergir o que é mais característico da existência do grupo e de cada um dos membros do grupo, e não as expectativas, crenças e anseios do psicoterapeuta. 


\section{Referências}

HEIDEGGER, M. Sobre a essência do fundamento. In:

Conferências e escritos filosóficos - Col. Pensadores XLV. Trad. Ernildo Stein. São Paulo: Abril Cultural, 1973.

. Ser e tempo. Trad. Márcia de Sá Cavalcante. Petrópolis: Vozes, 1998.

2001.

Sein und Zeit. 18. Auflage; Tübingen: Max Niemeyer,

- Os Conceitos fundamentais da metafísica: Mundo, Finitude, Solidão. Trad. Marco Antônio Casanova. Rio de Janeiro: Forense Universitária, 2003a.

A Essência da Linguagem. In:

A caminho da

linguagem. Trad. Márcia de Sá Cavalcante Schuback. Petrópolis: Editora Universitária São Francisco/Vozes, 2003b.

O Caminho para a Linguagem. In:

A caminho da

linguagem. Trad. Márcia de Sá Cavalcante Schuback. Petrópolis: Editora Universitária São Francisco/Vozes, 2003c.

. What is called thinking? Transl. J. Glenn Gray. New York: Perennial/Harper Collins, 2004.

. Zollikoner Seminare. 3. Auflage; Frankfurt am Main: Vittorio Klostermann, 2006.

. O Eterno Retorno do Mesmo. In: Nietzsche I. Trad. Marco

Antônio Casanova. Rio de Janeiro: Forense Universitária, 2007.

. Introdução à filosofia. Trad. Marco Antônio Casanova. São Paulo: Martins Fontes, 2008.

JARDIM, L. A Preocupação liberadora no contexto da prática clínica. Trabalho de Conclusão de Curso não publicada - PUC-SP. São Paulo, 2003.

Um estudo sobre as afinações a partir da ontologia

fundamental de Martin Heidegger: contribuições para as práticas clínicas. Dissertação de Mestrado não publicada - PUC-SP, São Paulo, 2009.

LISPECTOR, C. Uma aprendizagem ou livro dos prazeres. Rio de Janeiro: Rocco.

Endereço para correspondência

Luís Eduardo Franção Jardim

Rua Capote Valente, 1394, 05409-003 Pinheiros, São Paulo, SP, Brasil

Endereço eletrônico: luisfjardim@yahoo.com.br

Recebido em: 28/11/2011

Reformulado em: 18/06/2012

Aceito para publicação em: 21/06/2012 
Acompanhamento do processo editorial: Ana Maria Lopez Calvo de Feijoo

\section{Notas}

* Mestre em Psicologia Clínica pela PUC-SP e doutorando do Instituto de Psicologia da USP-SP. Membro pesquisador do Laboratório de Estudos do Imaginário (LABIUSP) da Universidade de São Paulo-SP. Membro e Coordenador da área de Pesquisa Acadêmica de Fenô\&Grupos e é professor e supervisor clínico de Fenomenologia na Universidade Paulista UNIP em São Paulo.

${ }^{1}$ Optou-se por fazer modificações da tradução brasileira de Heidegger (1998) e utilização do termo original alemão Dasein (ou a tradução literal ser-aí) ao invés de pre-sença, com o intuito de evitar distorções de sentido. O mesmo se aplica para os termos afinação (Stimmung), ao invés de humor e aí (Da) ao invés de pré. As modificações foram feitas com base no texto original Heidegger (2001), embora tenha sido mantida a paginação da versão brasileira para o viabilizar o acesso para o leitor. 